\title{
The Influence of Multimedia with Autistic Learners from the Teachers Perception
}

\author{
https://doi.org/10.3991/ijim.v14i14.12943
}

\author{
Sarah Bakr M Omar, ${ }^{(凶)}$, Koo Ah Choo, \\ Multimedia University, Selangor, Malaysia \\ Azman Bidin, \\ University Malaysia Kelantan, Kelantan, Malaysia
}

\begin{abstract}
The purpose of the study is to explore the perspective of teachers on the use of tablet-based applications with young autistic children through a qualitative case study approach. Eight schoolteachers were interviewed for the study. This paper reports the findings of teachers' perceptions towards the Autism Aid application with their learners, which has been designed based on their cognitive ability and school curriculum, e.g., self-management skills. The findings showed that generalization based on the design of tablet applications used could be problematic due to the limited number of participants, as well as the potential impact of teaching philosophies and previous experiences. Second, the results have shown that motivation, the human-model, and the use of technology in the classroom affected children's learning outcomes.
\end{abstract}

Keywords - Tablet-based application, evidence based, teachers' perceptions, video-modelling.

\section{$1 \quad$ Introduction}

Research-based practical evidence has demonstrated a positive association with the use of tablet-based applications and children's learning skills improvement. Autistic children have difficulties in imitating behavior tasks due to a lack of visual presentation, which leads to a delayed response that can affect their learning process. As autistic children are known as visual learners, teaching skills through multimediapresentations can improve their learning skills better than traditional teaching methods [1]-[3]. Improved use of visual tablet-education applications can be of great benefit to both teachers and young autistic children in the classroom. Tablet-education application is an enhanced learning resource for teaching skills, as well as learning material [4]. Previous studies have shown that using the tablet-application has allowed teachers to perform better in teaching [5], [6]. As stated in [7], the tablet-based educational application is a helpful strategy that allows teachers to think differently, and also assist the learning process of young children. It is worth noting that designing and developing an application for autistic children comes with different criteria based 
on the characteristics of the children, such as cognitive functions and the degree of their intelligent quotient [8].

\section{$2 \quad$ Literature Review}

Research-based evidence has emphasized on teacher's perception on the use of visual support system tablet-based application with young autistic children. The problems arise due to the lack and absence of visual symbolic and representations to imitate skills. However, the educational application has been proven to improve the learners' ability. Evidence-based practices in previous studies reported that the use of a video component is an effective method to teach behaviors [9], [10]. In recent years, tablet applications became more widely utilized in the educational classroom setting. A study by [11] has revealed that educational application combines the benefit of visual and physical support to help the teachers manage behavioral challenges that they faced during teaching. Therefore, to develop the application, recent studies [12][14] claimed that specific guidelines and principles helped improve children learning outcomes.

The guidelines emphasized that the choice of color, shape, and layout to present the information are crucial for the learning process. For example, according to [15], autistic children can be obsessed with and sensitive to specific colors. This is further supported by [12], who defined how the colors should look like, i.e., the colors should be within a particular range of soft and mild colors. The UK Department of Health created a methodology for the preparation of documents for people with learning disabilities. The development and design of the applications have to follow specific guidelines of the methodology, such as the video must be big enough for the users to see, the words must be clear and use short sentences. According to Chambers, multimedia cognitive learning involved a particular instruction design where task analysis behavior helped learners to continue learning without affecting their cognitive load and learning performance [5]. Meanwhile, according to Pavlov [12], age and behavior characteristics can determine the application design. For example, the design application should fall into one of the categories, i.e., entertainment, teaching tutorial, and supported collaborative learning. The educational application should be designed to cater to the needs of young autistic children. Miller [16] stated that multimedia presentations such as video and written texts help to engage children in appropriate cognitive processes during learning, whereby autistic children learn from visual information processes. The Cognitive Theory of Multimedia Learning by Mayer stated that visual information enables learners to "select relevant information" comprising of words or pictures, "organize [them] into coherent mental representations" and "integrating [the] information with relevant prior knowledge activated from long-term memory" [34]. Three basic elements that allow learners to succeed in learning through video tutorials are i) it should be short and chunked, ii) it should be comprised of modality and personalization, and iii) it should include narration and spoken conversationally [14]. 
Video tutorial is a highly effective instruction learning material. The use of visual presentation as a video allows children to observe and imitate the behavior tasks/actions. Such detailed guidance of the concepts of task behavior analysis will allow learners to continue learning without affecting their cognitive load and learning performance. For example, Chorianopoulos and Giannakos [17] stated that video is rich in contents that can connect the ideas and associated with learning instructional design. Such instructional designs that are based on the analysis of task behavior increase the success of learning behaviors [2]. This process alone can be challenging for autistic children to apply; however, Bandura's Social Learning Theory has shown that these concepts can be applied and incorporated based on video modeling (VM). Raedts and his colleagues [18] confirmed that video modeling is one of the most effective strategies to improve, organize the performance, and various skills with autistic children, such as social, communication, daily living skills, and other critical areas of needs. The important part with design application, according to [19] is to choose the appropriate tool to increase their ability to perform their daily living skills, then usability of the application with autistic children.

Raedts et al. [18] said that children could comprehend the content and interact through tablet-application. Rasit et al. stated that cognitive functions have contributed to support children, enabling them to comprehend content through video-modeling [20]. Bandura's Social Learning Theory has emphasized that humans (children) can learn by observing and imitating the behaviors. The basic procedure roles to develop tablet-based lessons should be short and precise, with crucial features for instant video, audio, and some written texts, to strengthen and boost children's skills acquisition beyond their capabilities. The lesson structures should be in a natural and flexible mode, fruitful, certainly enriching, and conceiving instrument to fulfill their need [3], while Mayer Cognitive Theory of Multimedia Learning has indicated that multimedia presentation could be an effective way of engaging learners through the use of visual instructions channel in the learning process [21]. Similarly, the benefit of using the educational application will increase the enthusiasm of children, increase their commitment to learning, and allow children to establish and appreciate the relationship between video-modeling and improving their comprehension of behavior.

However, the multimedia and usability of tablet-device application have become one of the most compatible tablet-device that has provided a positive outcome for young autistic children who neglect imitation behaviors and pay attention to target behavioral tasks. Numerous studies have illustrated the significance of visual structure for autistic children to enable them to engage and interact with the contents [8], [22]. Video-modelling is a sequential instruction learning content strategy used, for example, to substitute thinking loud for learners to organize their knowledge, thoughts, and how to do so in a particular procedure that contrasts with conventional methods. The learning cycles are important processes for imitating skills. Therefore, the advantage of this strategy is direct instruction, the learning cycles, particularly for joint attention and retention of information, which have a positive impact on skills performance. A case study design conducted by Conn [23] aimed to examine teachers' perception of the tablet device, a learning tool strategy with Autism Spectrum Disorders (ASD). The results from teachers' observation were positive on 
the use of the tablet device-based application learning communication and social skills of their students with ASD. For example, a study conducted by [24] focused on teachers' attitudes toward the use of interactive technologies, such as tablet devices.

The findings of the study showed that there are no benefits to the use of tablets as teachers do not use them in the long term. A case study by [25] was designed to explore the perception of preschool teachers using a tablet-application in the classroom to address communication issues with their students. Teachers in the study stated that they preferred and were pleased with the conventional teaching method since it encouraged students to use and present a variety of learning materials at convenient times. However, the results of the study showed that the teachers were more interested in using alternative devices, such as tablet-application, compared to the other teacher and speech therapist who still preferred the Picture Exchange Communication System (PECS). Nevertheless, generalization based on the nature of the tablet-application may be difficult due to the sample size of the participants, as well as the possible influence of teaching philosophies, identity, and previous experiences. Some of the participating teachers did not seem to have extensive tabletapplication training, and the experience reported in the study was not long enough to make these practitioners masters of their craft.

\section{Autism Aid Design Framework}

A case study was conducted to establish the Autism Aid application to be used in a classroom setting based on the school curriculum (Pengurusan Kehidupan Masalah Pembelajaran). The tablet-based application was installed as a learning enhancement tool (Figure 1), in line with the curriculum for children at the preschool age. The framework design of the Autism Aid application followed the recommendation of [12] to develop a software application for learners with specific disabilities (autistic users). The accessibility guidelines were divided into four sections consisting of the "graphical layout", "structure", "navigation user", and "language indication". The guidelines instruction will help learners to hold their attention and engage children in terms of its relevance to the children's cognitive ability. Such instructions and guidelines on the accessibility features reflect the technology in the tablet-based application Autism Aid. This study aimed to examine the teacher's perspective on the use of Autism Aid application in the early intervention of young autistic children. This study presents an evidence-based practice for the importance of Autism Aid to assist in young autistic children learning. 


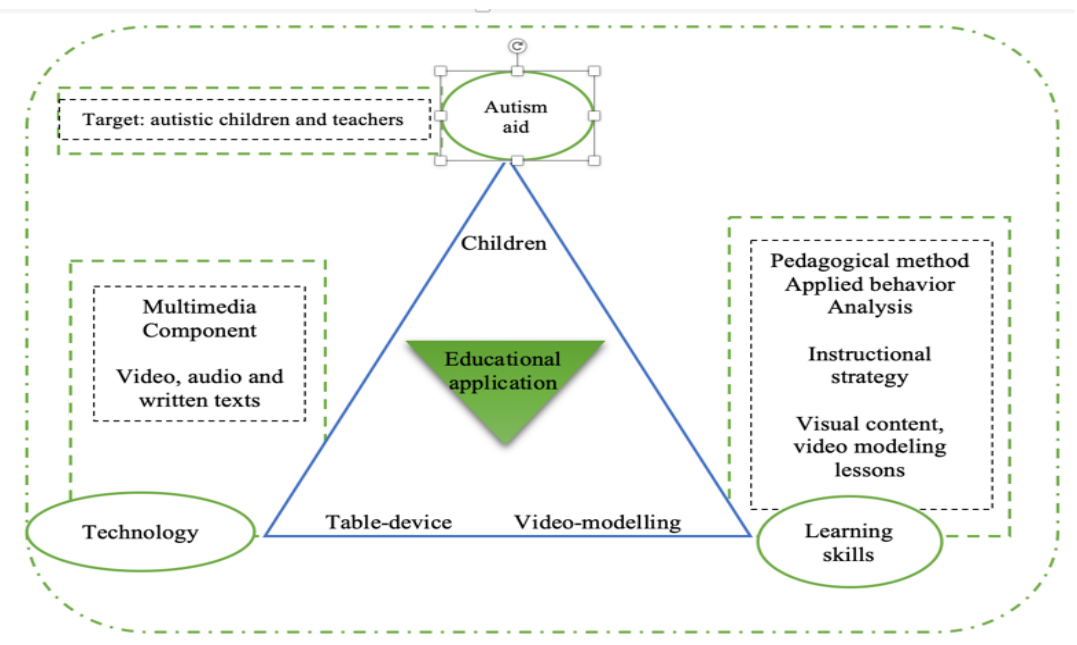

Fig. 1. Conceptual Framework Autism Aid Application

\section{Methods and Materials}

\subsection{Participants}

The participants were comprised of a group of eight school teachers who specializes in teaching autistic children. The school teachers were male and female, with ages ranging from 23-37 years old and taught at preschools located in Kuala Lumpur, Malaysia. The teachers used English fluently to teach the children. The program comprised of the researcher, school principal, and school teachers.

\subsection{Procedures}

The duration of the project was five months. Initially, the researcher informed the teachers on how to use the application. The data collection methods employed include; 1) observation note used for each child, 2) interview with school teacher and administrator towards the usability of the application with autistic children, and 3) children's documents. Open-ended interviews were conducted to understand teachers' perceptive on the use of educational tablet-applications as a teaching strategy designed and developed for children. Data from the interview was analyzed using thematic analysis [21] and ATLAS TI software.

\subsection{Materials}

The program was designed on the basis of one-to-one Applied Behavior Analysis. The classroom contained a child-size table and chairs, as well as any materials relevant to the sessions, and the tablet was produced by Samsung tablet-device to 
watch the video models of the tasks. The tablet was at the appropriate eye level for the child's classroom setting. Teachers have abled to express their opinion on the use of tablet-device in the classroom. Teachers have used the advantage of the videomodelling application to teach, a skill that usually difficult for them to explain and manage effectively with normal teaching methods. The potential use of tabletapplication to support teaching and learning has benefits teachers to use a different type of teaching material sources.

\subsection{Video-content of autism aid}

The application included two types of videos, whereby the first video showed the entire behavior skills, and the second video showed the step-by-step procedure of the behavior skill, such as how to wash hands and ablution based on Behavior Task Analysis (BTA). At the end of each lesson, there is an exercise for each learning behavior. The purpose was to give the children a complete understanding of how the skills were performed. Three videos were designed to focus on behavioral chain techniques. For example, the first step was to turn on the water, followed by the addition of soap, rinsing the soap off their hand and turn off the tap water, lastly, drying their hands.

\subsection{Training session for the teachers}

The researcher conducted a training session for nine teachers on how to use the tablet-based application. The session was started by giving them a general overview of the research and an overview of the training subjects' main points on how to use the application. During the session, the teachers were provided with specific information and the key points of the application. At the same time, the researcher demonstrated the procedures of the application (Figure 2) and any other related information that the trainees need to be aware of. Then, the trainees were allowed to be involved with the application, e.g., each one of the participants was given a handson with the tablet application. It allowed them to understand the application and to create a better learning environment by guiding the trainees to familiarize themselves with the application. The necessity for such a training session was to enable the teachers (caregivers) to know how to use the application because they are the once who will be directly involved with the children while the author is just an observer. 

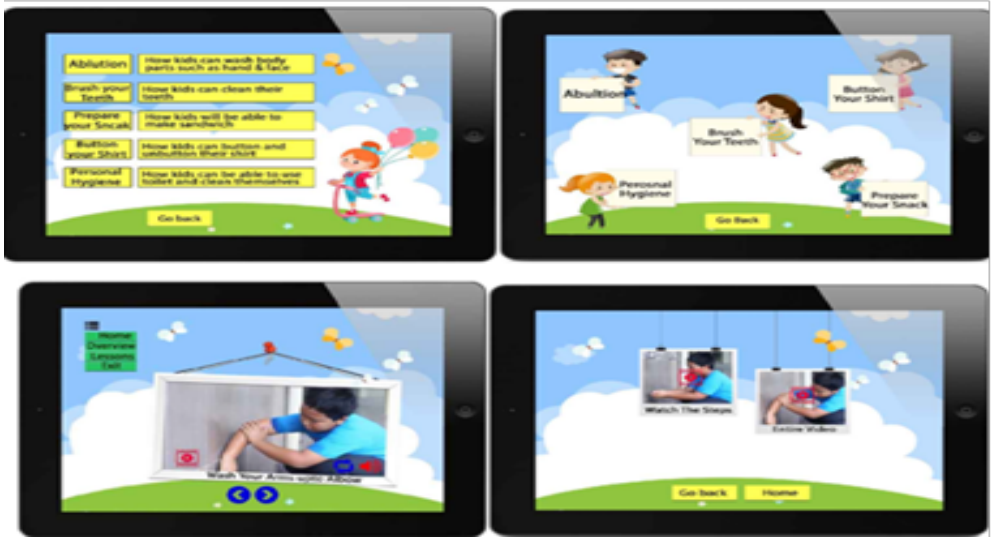

Fig. 2. Autism aid application

\section{$5 \quad$ Result}

The descriptive explanatory case study was used to determine the factors that impact teacher's perception on the use of tablet-based application with autistic children. The teachers' statements recorded during the interview were transcribed verbatim, and pseudonyms were used to hide identity, e.g., participant teacher 1 and 2 . The study results would be discussed and presented by answering the research questions.

\subsection{Teachers' perceptions towards using tablet-device in classroom with their learners}

The results have shown that it would be difficult to make a generalization based on the nature of tablet-application due to the limited number of participating teachers, as well as the potential influence of teaching or practice philosophy and previous experiences. It indicates that there is a difference of opinion between respondents (teachers) regarding the application of tablet devices to teach autistic children. This can be substantiated by the views expressed by them. For instance, teacher 1 stated, "Children can utilize technology with supervision for a limited time. Not using too much is better". Teachers have believed that utilize tablet-device in classroom should be in balance used with others teaching materials, teacher 2 said that " $50 / 50$ we don't want children to depend on tablet-device application". Although the tablet is an excellent reinforcement tool, some children do not require the tablet-application. The researcher observed that experienced teachers were the ones who supported the use of the device to teach while the freshers were skeptical about it. This is because the latter just want to apply the method they learned during the period of their training.

Therefore, the data showed that $50 \%$ of the teachers thought that utilizing tablets in the classroom will distract the flow of the lessons, while $8 \%$ of teachers became frustrated due to utilize tablet-device in the classroom. After the teachers had trained 
to use Autism Aid, they changed their idea concerning the benefits of tablet-based educational applications for their students. The school teachers have noticed the difference between the use of high-tech and low-tech applications in the students' learning process. Based on data analysis, $6 \%$ of the teachers believed in the use of technology. Video-component as teaching material has been effective with autistic children based on $26 \%$ of the children could imitate the skills.

\subsection{Teachers perception on the impact of tablet application in the development of daily living skills of autistic children}

According to the teachers, the use of video-modeling has helped children to learn. Respondent teachers 1 and respondent teachers 2 for example, described the video as "visual and have clear pictures. They also consented by stating, "I think yes, actually video-modeling can help children to imitate the skills because [autistic] children will see the movement, and then they start to imitate the action". Teacher 2 stated that "children can master [the skill] after they used it". This finding is similar to [26], confirming that video-application can improve learning, maintain a daily living, and increase the productivity and capabilities of children. Another finding showed that the use of video-based tablet-app with autistic children to teach skills has the leverage to support education teaching methods and inspiration for developing daily living skills [27].

\section{Discussion}

The objective of the study was to develop a software application for the researcher to construct a teacher's perception of using tablet-application with autistic children. The goal of the study is to explore the perspective of teachers on the use of Autism Aid for young autistic children. The study found that there is a mixed of opinion between respondents (teachers) on the use of a tablet device to teach autistic children. The researcher observed that the experienced teachers are the ones who support the use of the device to teach while the freshers are doubtful about it. This is because the latter only want to apply the process they have learned during their training. Teachers have emphasized the importance of the motivating element to energize children to learn. Video-modeling is one of the most effective approaches for children through observing behavior and engaging in learning material. It will contribute to improving learning. Initially, the respondents (teachers) do not feel comfortable with the idea of tablet-device due to previous experiences. Teachers have reported that the use of tablet-device in the classroom will disturb the flow of the classroom and other children too. The teachers also believed that few children have negative emotional actions that might lead them to abuse themselves. This finding supports the study of Halabi [28] regarding the incidence of anxiety, frustration, and unexpected behaviors due to the use of tablets in the classroom routine. These beliefs came from the previous experiences that teachers had. Other teachers have agreed on the benefits of tablet-application, where children could observe and watch the target behaviors. 
Children can imitate target behavior directly from the video-model, able to apply and master the behavior in practical sessions. However, the school teachers are concerned that tablet-application could change the classroom environment routine instructions. These findings are aligned with the findings of Quintana et al. [11] that stated educational application involving visual and physical support helped the teachers to manage challenges that they face during teaching. The teachers support the use of tablet-application in the classroom to improve children's learning skills, and according to the studies [29], [30], the tablet-device application is an effective tool for children improvement and effective pedagogical techniques for assisting children in the classroom.

This finding confirmed that tablet-application is an effective learning platform to support children's development [31], [32]. The evidence from teachers was supported by [22], who found that educational tablet-application, including video-modeling is a potentially useful method of teaching young autistic children in multi-step tasks, with a high level of independence and direct guidance.

\section{Conclusion}

The study is related to the use of educational applications for teaching autistic learners and teachers' perceptions toward tablet-applications with their learners. The study was conducted via interviews and observation methods that helped to gain more understanding of teachers' views, as well as having observed their teaching methods during the implementation of the application in the classroom. The field of teaching strategy frequently changes due to the fast and rapid innovations of technology with different types. This means the principles of teaching and training teachers should be in line with new developments because the use of it has an advantage for both teachers and learners. The integration of tablet-applications can lead to an improved teaching method for autistic children. The use of high-tech applications is acceptable by teachers, and they are willing to use it. The conceptual and pedagogical teaching method based on the use of educational applications supports young autistic children. Once the teachers managed to grasp a substantial understanding of the use of the educational application as an enhancement learning tool, both teachers and learners will gain the benefit of it. The scenario will fit their pedagogical beliefs and attitudes used in different activities. The study defined the application design framework as a content delivery education application system for autistic children. Autism Aid could be manipulated according to the teachers' goals and allows the children to adapt it. Future work will concentrate on the expansion of the e-learning content delivery education framework with a new approach and classification scheme to communicate with parents and therapists.

In conclusion, the observation of video data analysis reveals that teachers believe in utilizing and making use of the tablet-application in the classroom because it provides access to the school curriculums. 


\section{Acknowledgement}

This research did not receive any financial support. The research team would like to thank the reviewers of the paper and the teachers involved in this study.

\section{References}

[1] A. Constantin, H. Johnson, E. Smith, D. Lengyel, and M. Brosnan, "Designing computerbased rewards with and for children with Autism Spectrum Disorder and/or Intellectual Disability," Computers in Human Behavior, 75, pp. 404-414, 2017. https://doi.org/10.1016/j.chb.2017.05.030.

[2] A. Labrie, "The use and perceived benefits of computer tablets among special educators," Ed thesis, Northcentral University, Arizona, 2015 http://search.proquest.com.libproxy.ucl.ac.uk/education/docview/1728057736/abstract/6D A495C0824544F7PQ/2

[3] D. Wood, J. Bruner, and G. Ross, "The role of tutoring in problem solving," Journal of Child Psychology and Psychiatry, vol. 17, no. 2, pp. 89-100, 1976.

[4] S. Stuart and J.C. Collins, "Special education transition services for students with autism," Special Education Transition Services for Students with Disabilities (Advances in Special Education), vol. 35. pp. 99-116, Emerald Publishing Limited, 2019. https://doi.org/10.1108/S0270-401320190000035014.

[5] D. J. Chambers and R. G. Berlach, "Assistive technology and teacher assistants," Working with Teaching Assistants and Other Support Staff for Inclusive Education (International Perspectives on Inclusive Education), vol. 4, pp. 219-239, 2015.

[6] N. Jones, "Instructional technology usage in early learning environments: The influence on environmental access, training, parental use and education," Electronic Theses \& Dissertations Collection, Atlanta University \& Clark Atlanta University, 2015.

[7] H. J. Sossong, "The impact of using video modeling on skill acquisition and transfer to community-based settings when teaching young adults with autism using video modeling," 2012.

[8] L. Neely, M. Rispoli, S. Camargo, H. Davis, and M. Boles, "The effect of instructional use of an $\mathrm{iPad}\left({ }^{\circledR}\right.$ on challenging behavior and academic engagement for two students with autism," Research in Autism Spectrum Disorders, vol. 7, no. 4, pp. 509-516, 2013.

[9] B. Drysdale, B., C. Y. Q. Lee, A. Anderson, and D. W. Moore, "Using video modeling incorporating animation to teach toileting to two children with autism spectrum disorder," Journal of Developmental and Physical Disabilities, vol. 27, no. 2, pp. 149-165, 2015. https://doi.org/10.1007/s10882-014-9405-1.

[10] L. Fiorella and R. E Mayer, "Effects of observing the instructor draw diagrams on learning from multimedia messages," Journal of Educational Psychology, vol. 108, no. 4, pp. 528546, 2016. https://doi.org/10.1037/edu0000065.

[11] E. Quintana, C. Ibarra, L. Escobedo, M. Tentori, and J. Favela, "Object and gesture recognition to assist children with autism during the discrimination training," Iberoamerican Congress on Pattern Recognition, vol. 7441 LNCS, pp. 877-884, 2012. https://doi.org/10.1007/978-3-642-33275-3 108.

[12] N. Pavlov, "User interface for people with autism spectrum disorders," Journal of Software Engineering and Applications, vol. 07, no. 02, pp. 128-134, 2014. https://doi.org/10.4236/jsea.2014.72014. 
[13] B. Chen, "Mobile APP interface design process analysis," Proceedings of the 2018 International Workshop on Education Reform and Social Sciences (ERSS 2018), pp. 353356, 2019. https://doi.org/10.2991/erss-18.2019.69.

[14] R. E. Mayer, "Research-based principles for designing multimedia instruction overview of multimedia instruction," in Infusing Psychological Science into the Curriculum, V. A. Benassi, C. E. Overson, and C. M. Hakala, Eds., American Psychological Association, 2014.

[15] A. Franklin, P. Sowden, R. Burley, L. Notman, and E. Alder, "Color perception in children with autism," Journal of Autism and Developmental Disorders, vol. 38, no. 10, pp. 18371847, 2008. https://doi.org/10.1007/s10803-008-0574-6.

[16] D. J. Miller, "Educator perceptions of visual support systems and social skills for young adults with autism spectrum disorders," Ed. D thesis, Walden University, 2016.

[17] K. Chorianopoulos and M. N. Giannakos, "Usability design for video lectures," Proceedings of the 11th European Conference on Interactive TV and Video, EuroITV 2013, (May), 163-164, 2013. https://doi.org/10.1145/2465958.2465982.

[18] M. Raedts, E. V. Steendam, L. D. Grez, J. Hendrickx, and A. Masui, (2017). "The effects of different types of video modelling on undergraduate students' motivation and learning in an academic writing course," Journal of Writing Research, vol. 8, no. 3, pp. 399-435, 2017.

[19] S. Piccin, A. Crippa, M. Nobile, A. Y. Hardan, and P. Brambilla, "Video modeling for the development of personal hygiene skills in youth with autism spectrum disorder," Epidemiology and Psychiatric Sciences, vol. 27, no. 2, 127-132, 2018. https://doi.org/10.1017/S2045796017000610.

[20] R. M. Rasit, S. H. Hamjah, S. R. Tibek, F. M. Sham, M. F. Ashaari, ... A. Ismail, "Educating film audience through social cognitive theory reciprocal model," Procedia Social and Behavioral Sciences, vol. 174, pp. 1234-1241, 2015. https://doi.org/10.1016/j.sbspro.2015.01.742.

[21] S. D. Sorden, "The cognitive theory of multimedia learning," Handbook of Educational Theories, pp. 1-31, 2012. https://sorden.com/portfolio/sorden_draft_multimedia2012.pdf

[22] E. Chaffee, T. Ho, and K. Ng, "Pilot study: Assistive technology as a vocational support for individual with autism spectrum disorder," Graduate Master's Theses, Capstones, and Culminating Projects, 288, 2018. https://scholar.dominican.edu/masters-theses/288

[23] J. J. Conn, "Teacher perceptions of the impact of digital photo stories on students with autism spectrum disorder," 2015.

[24] N. M. Razali, H. Toran, S. Kamaralzaman, N. M. Salleh, and M. H. M. Yasin, “Teachers' perceptions of including children with autism in a preschool," Asian Social Science, vol. 9, no. 12, pp. 261-267, 2013. https://doi.org/10.5539/ass.v9n12p261.

[25] D. E. Tamakloe, "Preschool teachers and support staff's experiences in using assistive technology in serving preschool children with disabilities," Ph.D dissertation, Washington State University, p. 149, 2015.

[26] S. L. Odom, J. L. Thompson, S. Hedges, B. A. Boyd, J. R. Dykstra, ... A. Bord, "Technology-aided interventions and instruction for adolescents with autism spectrum disorder," Journal of Autism and Developmental Disorders, vol. 45, no. 12, pp. 38053819, 2015. https://doi.org/10.1007/s10803-014-2320-6.

[27] F. Shic and M. Goodwin, "Introduction to technologies in the daily lives of individuals with autism," Journal of Autism and Developmental Disorders, vol. 45, no.12, pp. 37733776, 2015. https://doi.org/10.1007/s10803-015-2640-1. 
[28] A. L. Halabi, "Understanding the use of tablet devices in the classroom when teaching a group of learners diagnosed with autism," M.S. thesis, Iowa State University, no. 14385, 2015. https://lib.dr.iastate.edu/etd/14385

[29] C. Piatt, M. Coret, M. Choi, J. Volden, and J. Bisanz, "Comparing children's performance on and preference for a number-line estimation task," Journal of Psychoeducational Assessment, vol. 34, no. 3, pp. 244-255, 2015. https://doi.org/10.1177 10734282915594746.

[30] S. Omar and A. Bidin, "The impact of multimedia graphic and text with autistic learners in reading," Universal Journal of Educational Research, vol. 3, no. 12, pp. 989-996, 2015. https://doi.org/10.13189/ujer.2015.031206.

[31] D. F. Cihak, D. McMahon, C. C. Smith, R. Wright, and M. M. Gibbons, "Teaching individuals with intellectual disability to email across multiple device platforms," Research in Developmental Disabilities, vol. 36, pp. 645-656, 2015. https://doi.org/10.1016 /j.ridd.2014.10.044.

[32] M. Khemaja and A. Taamallah, "Towards situation driven mobile tutoring system for learning languages and communication skills: Application to users with specific needs," Educational Technology and Society, vol. 19, no. 1, pp. 113-128, 2016.

[33] F. D. D. Reed, S. R. Hyman, and J. M. Hirst, "Applications of technology to teach social skills to children with autism," Research in Autism Spectrum Disorders, vol. 5, no. 3, pp. 1003-101, 2011. https://doi.org/10.1016/j.rasd.2011.01.022.

[34] R. E. Mayer, and P. A. Alexander, "Handbook of research on learning and instruction," 2018. https://doi.org/10.4324/9781315736419.

\section{Authors}

Sarah Bakr M Omar, is now Ph.D. candidate in E-learning Technologies at Faculty of Creative Multimedia (FCM). Multimedia University, Malaysia 63100 Cyberjaya, Selangor. Her research interest is to study the use of tablet- based educational application and developing and design digital learning contents interactive applications.

Associate prof. Dr. Koo Ah Choo, Multimedia University. Faculty of Creative Multimedia 63100 Cyberjaya, Selangor. Her research interests are mobile and ubiquitous learning, digital creation of interactive applications.

Dr. Azman Bidin Senior Lecturer. Department of Humanities and Social Sciences. Centre of Language Studies and Generic Development, University Malaysia Kelantan. His research interest's media communication, entertainment education and media effect.

Article submitted 2020-01-20. Resubmitted 2020-02-19. Final acceptance 2020-02-20. Final version published as submitted by the authors. 